\title{
Founding Team Performance: Influences of Founding Team Diversity
}

\author{
Qian Ye \\ University of Wisconsin Parkside
}

This paper explores the influences of founding team diversity on team performance. Drawing on studies in the diversity literature, this paper suggests that successful founding team formation is under the influences of actual and perceived team diversity at both surface and deep levels. It proposes that deep-level diversity among founders is not unfolded at the early stage; therefore surface-level diversity impacts outcome of team formation, a relationship moderated by interpersonal feelings. Strong interpersonal feelings stimulate founder collaboration, resulting in successful founding team formation.

Keywords: founding team diversity, team performance, deep-level diversity, surface level diversity, founding team formation

\section{INTRODUCTION}

An extensive body of research indicates that that founding team diversity exerts strong influences on team formation (e.g.Forbes, Borchert, Zellmer-Bruhn, \& Sapienza, 2006), and performance (e.g.Ensley \& Hmieleski, 2005; Randel \& Jaussi, 2003). However, a continuing debate in literature is whether diversity of a founding team is beneficial to the team performance. One view argues that diverse founding teams have a broader set of skills and a wider variety of information and experiences, therefore, are better suitable for complex and uncertain environments so that they are more successful than homogeneous teams (Eesley, Hsu, \& Roberts, 2014). A second view holds that divers teams are less cohesive and team conflicts easily arise, therefore, ineffective (Yu, 2002), which indicates that similarity rather than diversity among members is more beneficial for team performance. In addition, recent research has found that high diversity in gender or skills might be negative attributes in R\&D teams (Martinez, Zouaghi, \& Marco, 2017)

Although prior research has improved our understanding of founding team diversity and its relationships associated with team formation and performance, previous research has several limitations. First, prior studies are confined to the two dimensions of founding team composition: heterogeneity and homogeneity. Few studies go beyond the superficial distinguishment (functional vs. social characters) by looking at the actual and perceived deep-level diversity within a founding team. In the diversity literature, one prominent view that conceptualizes diversity in terms of differences in surface-level attributes - those are apparent without interpersonal interaction (age. gender, education, skills), and deep-deep level attributes - those are not readily apparent without interpersonal interaction (values, attitudes, beliefs) (Harrison, Price, Gavin, \& Florey, 2002). However, diversity at surface level may not reflect deep-level differences. Diversity is multifaceted, representing different sources (e.g., demographic, human capital, and social capital) and operating at different levels of analysis (Tasheva \& Hillman, 2019). Founding teams are the initial teams that found and manage organizations for the first several years of operations (Sine, 
Mitsuhashi, \& Kirsch, 2006). Drawing on this definition, in this paper, I define founding teams are the initial teams that found and manage new ventures for the first several years of operations. From the initial team start-up stage to later team operation and management stage, founding teams experience idiosyncratic dynamics. Founding team members must closely integrate with each other to cope with complex situations and uncertainty. In this process, intra-team communication becomes an important source of information in decision-making, which also becomes an important source of information that reveal various team members' deep-level attributes. We do not know the influences of the revealed deep-level diversity on consequent founding team integration, functioning, and performance. However, these influences cannot be neglected. In diversity literature, deep-level diversity is found to be more important than surface-level diversity in determining team integration and performance (Bell, 2007). Without distinguishing the influences of diversity at both surface and deep levels, our understanding of founding team effectiveness is biased toward an incorrect assumption that the surface-level diversity, per se, reflects the underlying differences in individual prejudices, biases, stereotypes, thinking, or problem-solving capability etc., which indeed it does not. It is important to distinguish the influences of deep vs. surface level diversity within founding teams.

Second, in the current founding team diversity literature, very few studies have explored the interdependence relationship between founding team diversity and affective structure. In the last decade, entrepreneurship literature begins to document an overlap between entrepreneurial activities and affect (Baron, 2008; Cardon, Wincent, Singh, \& Drnovsek, 2009). Affect will not only influence an entrepreneur's decision to "buy into" a business idea, but also will play a role in bringing stakeholders together to sustain the venture (Chen, Yao, \& Kotha, 2009; Sudek, 2006). Casciaro \& Lobo's study (2008) reveals that interpersonal feelings impact tasked-related (instrumental or functional) networks in entrepreneurial firms. This study shows the coexistence of affective and instrumental (functional) goals within the same taskrelated tie, and positive and negative feelings emerged as important predictors of task interaction. We need more studies in this area to understand whether members of founding teams also combine both instrumentality and affect in their team relationships. Then understand how interpersonal feelings influence the trade-offs during founding team formation.

This paper first investigates the influence of diversity on founding team formation and its performance at both actual surface and actual deep (psychological and cognitive) levels. At the very early stage of founding team formation, when deep-level diversity is not unfolded yet, surface-level diversity reflects the effects of perceived diversity on team integration. This relationship is moderated by interpersonal feelings among founders. Stronger interpersonal feelings stimulate team collaboration and facilitates successful founding team formation.

This paper is organized as follows. The next section provides a conceptual and the theoretical background of diversity and founding team, including an overview of empirical findings. Next, a model of founding team formation and performance is presented, which is followed by developed propositions. Discussions, implications, and directions for future research are followed in the last part.

\section{DIVERSITY AND FOUNDING TEAM: AN OVERVIEW OF THEORETICAL AND EMPIRICAL FINDINGS}

\section{Related Constructs}

Founding teams are the initial teams that set up and manage organizations for the first several years of operations (Sine et al., 2006). Drawing on this definition, in this paper, I define founding teams as the initial teams that set up and manage new ventures for the first several years of operations. Team composition is the configuration of member attributes in a team (Levine \& Moreland, 1990). It has been documented that founding team composition has a powerful influence on founding team formation (Ruef, Aldrich, \& Carter, 2003) and performance (Randel \& Jaussi, 2003). Team composition affects the amount of knowledge and skills that team members apply to the venturing tasks. Team composition also influences the amount of effort team members apply to the task (Bell, 2007). Prior research on this topic have focused on the composition structure, the extent to which a given set of characteristics shared by team members. Two 
constructs have emerged to represent team composition: Diversity (heterogeneity) and Similarity (homogeneity).

Diversity is "any attribute that another person may use to detect individual differences" (Williams \& O'Reilly, 1998). In team composition literature, team diversity or similarity represent the extent to which members' characteristic are different or similar. One approach of team composition studies is measuring team members' difference and summing a score on a homogeneity-heterogeneity continuum. An underlying assumption of this approach is high heterogeneity reflects low homogeneity of a team. With this approach, founding teams are in general either diverse or similar. It does not demonstrate what types of characteristics on which members are diverse or similar. In the past decade, more and more founding team researchers have begun to take a different approach that distinguishes team member characteristics into two separate constructs: functional (instrumental) diversity and social demographic similarity. Functional diversity explains the difference among members with respect to achieved characteristics, such as skills, task expertise, and competencies in a particular area (e.g. finance, marketing, or operations etc.) (Milliken \& Martins, 1996). Demographic similarity explains team composition in terms of the homogeneity of member's social characteristics, such as race/ethnicity, education, age, sex, and marriage status etc. Following this approach, and for the reason of parsimony, this paper focuses only on the diversity of founding team composition. Accordingly, I distinguish diversity into two dimensions: functional and social demographic diversity.

\section{Surface vs. Deep Level Diversity}

In addition to the functional and demographic dimensions of diversity, one prominent view in the diversity literature conceptualized diversity regarding differences in surface and deep levels.

Surface-level diversity is differences among team members in characteristics readily apparent without interpersonal interaction (Jackson, May, \& Whitney, 1995). Such characteristics are easily observed and measured. For example, individuals can make reasonable estimates of the age, gender, racial/ethnic background, major, and education of someone else, so that individuals quickly define and differentiate themselves from others based on these easily observable differences (Harrison et al., 2002). Based on this conceptualization, both functional and social demographic diversity studied in most of, if not all, studies in the existing entrepreneurship literature are at the "surface" level, because these studies measure founding team member diversity simply basing on differences of characteristics that are easily define without considering diversity unfolded through in depth of interpersonal interaction.

Although current studies that have reported diversity effects on founding teams measure diversity at the surface level, most of them indeed are theorizing about "deep-level" other than "surface" level diversity effects. For example, these studies share a same underlying assumption of the presumed differences between people in their knowledge, competences, skills, attitudes, values, and beliefs derive from their different functional or social demographic backgrounds. Diverse founding teams are believed to be more effective than similar teams because members' diverse characteristics are assumed to provide the team with breadth of information sources, perspectives, and skill sets (Beckman, 2006). The underlying assumption of this argument is diversity at the surface-level reflects deep-level differences. However, deep-level differences cannot be captured by simply comparing members' apparent characteristics such as majors, education, or ethnicity. People with a same education background may have different capabilities of learning or communication skills, therefore, members with diverse functional backgrounds does not ensure the team benefit with a wide variety of information and experiences if the member's knowledge cannot be transformed into team-level cognitive resources. In a similar vein, bringing people with diverse ethnic backgrounds into a team does not ensure all members of the team share a same attitudes, personality, or beliefs.

Thus, in opposition to surface-level diversity, we need to conceptualize a diversity construct at deeplevel. Deep-level diversity refers to differences among team members' psychological characteristics, such as personalities (traits), values, preferences, and attitudes (Bell, 2007; Harrison et al., 2002). For entrepreneurial founding team, deep-level diversity reflects founders' attitude differences in venturing-task meaningfulness, outcome importance, overall commitment, and personal personalities and values. In 
addition to psychological characteristics, I propose that deep level diversity should also reflect cognitive differences among members, such as cognitive comprehensiveness, problem solving skills, thinking styles etc. Both psychological and cognitive differences do not appear when team members first meet, but such differences will unfold over time through members' interactions, and can be found out in behavior patterns, verbal and non-verbal communications, and in exchange of personal information.

Actual vs. Perceived Diversity

Actual diversity indicates actual discrepancy of characteristics among team members. Team diversity literature suggests that for interpersonal differences to be meaningful, these differences must be perceived. Previous studies also show that diversity effects rely on perceptions (Lawrence, 1997). Perceived deeplevel diversity would influence integrations of founding team, and team performance (Harrison et al., 2002).

Table 1 demonstrates a classification of multi-type diversities.

TABLE 1

\begin{tabular}{|l|l|l|}
\hline & \multicolumn{1}{|c|}{ Surface-level Diversity } & \multicolumn{1}{c|}{ Deep-level Diversity } \\
\hline \multirow{3}{*}{ Actual Diversity } & $\begin{array}{l}\text { Functional Diversity } \\
\text { (skills, knowledge, expertise etc.) }\end{array}$ & $\begin{array}{l}\text { Cognitive Diversity } \\
\text { (problem solving, thinking styles, } \\
\text { cognitive comprehensiveness etc.) }\end{array}$ \\
\cline { 2 - 3 } & $\begin{array}{l}\text { Social Demographic Diversity } \\
\text { (gender, sex, ethnicity etc.) }\end{array}$ & $\begin{array}{l}\text { Psychological Diversity } \\
\text { (value, belief, attitudes etc.) }\end{array}$ \\
\hline $\begin{array}{l}\text { Perceived } \\
\text { Diversity }\end{array}$ & Perceived functional diversity & $\begin{array}{l}\text { Perceived deep-level cognitive } \\
\text { diversity }\end{array}$ \\
\cline { 2 - 3 } & Perceived social demographic diversity & $\begin{array}{l}\text { Perceived deep-level psychological } \\
\text { diversity }\end{array}$ \\
\hline
\end{tabular}

\section{A MODLE OF FOUNDING TEAM PERFORMANCE: INTEROKAT IF DUVERSITY AND INTERPERSONAL FEELINGS}

In this paper, I am interested in diversity effects on founding team formation. It is well accepted that idiosyncratic dynamics within founding teams, particularly during the early team formation stage. Thus, paths that link team diversity to founding team formation, functioning, and performance are complex. These complexities are demonstrated in the theoretical model presented in Figure 1. Building on the existing founding team and diversity literature, this model proposes that the influences of diversity on founding team formation and performance at both surface (functional and social demographic) and deep (psychological and cognitive) levels. At the initial stage of founding team formation, when deep-level diversity is not unfolded yet, surface-level diversity reflects the effects of perceived surface-level diversity on team integration. Interpersonal feelings moderate the strength of influences of diversity on founding team formation. 


\section{FIGURE 1}

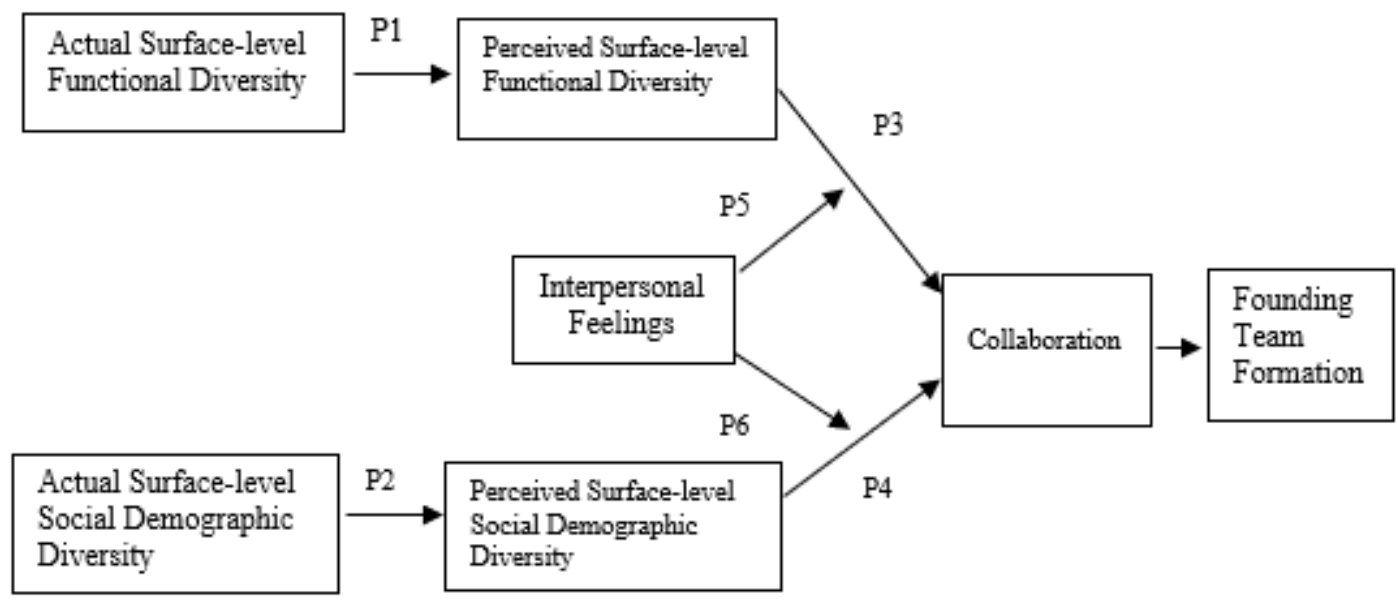

\section{Surface-Level Diversity and Founding Team Formation}

At the initial stage of founding team formation, since members' deep-level diversity has not unfolded, apparent difference characteristics at surface level take important role in founding team integration and formation.

In general, there are two general theoretical models explaining how surface-level functional and social demographic diversity impact founding team formation. One is a rational model from strategic perspective. With this perspective, founding team is formed by a rational calculation about the value each member can bring to the firm (Forbes et al., 2006). Each team member is desired because of his/her unique functional features that can fulfill a particular information/resource need of a team. The second explanation is an interpersonal model that predicts that founding team formation is determined by less social demographic diversity because less diverse social backgrounds enhance interpersonal attraction and social connection (Ruef et al., 2003).

\section{Rational Selection or Strategic Model}

Rational selection or strategic model explains that founding team formation is based on surface-level functional competencies desired by a team. Three theories that have been applied to explain the rational selection model: Human capital theory, social capital theory, and resource dependence theory.

Human capital theory suggests that specific knowledge, skills, and experiences reside within individuals and leads more productive and effective individual activities by providing them increased cognitive abilities (Becker, 1964). Everyone is added into a founding team because his/her knowledge and skills are valuable human capital that will contribute to consequent economic performance. Diverse human capitals are required because complementary competences among team members can help the new venture break through the barriers in various areas.

Social capital theory suggests that individuals are different in their abilities to make value from their social structures (Burt, 1992). When new venture is created, it always has liability of newness or smallness (Hannan \& Freeman, 1984). It is very difficult for new ventures to access to the required resources (Hannan $\&$ Freeman, 1984). Diverse functional features among members enables a founding team to access crucial information from members' social connection (Forbes et al., 2006).

Resource dependence theory holds that organizations survive to the extent they control critical resources (Pfeffer \& Salancik, 1978). Founding teams are formed based on resource needs of a new venture. Diverse abilities of member accessing critical resources impact founding team formation. Recent research has provided documents for this argument. For example, Kamm \& Nuric (1993) found that entrepreneurial team formation was motivated by resource acquisition. 


\section{Interpersonal Model}

There are several broad, deductive theories that have been used to support arguments about the consequences of surface-level social demographic diversity on founding team formation, such as social identity theory (Tajfel, 2010), and self-categorization theory (Turner, 1982). In general, researchers posit inverse relationships between surface-level social demographic diversity and founding team formation and performance. People are more likely to group with others who are more alike themselves because they anticipate their own values, attitudes, and beliefs will be valued and reinforced. Ruef et al (2003) found that teams in which members share similar social demographic backgrounds are dominant in U.S. entrepreneurial founding teams. Chander and Lyon (2001) also suggested that functional diversity is not a major consideration in entrepreneurial founding team formation, rather the most criteria is the common interest.

Actual Surface-Level Diversity and Perceived Surface-Level Diversity

No matter which model is chosen to set up a founding team, if actual surface-level functional and social demographic among members is meaningful to team formation, these diverse features must be recognized and valued during the initial team forming stage. Harrison, Price, and Bell (1998) study supported positive relationships between actual surface-level diversity and perceived surface-level differences.

Proposition 1: Actual surface-level functional diversity will have positive effects on perceived surface-level functional diversity.

Proposition 2: Actual surface-level social demographic diversity will have positive effects on perceived surface-level social demographic diversity.

\section{Perceived Surface-Level Diversity and Founding Team Formation}

As discussed earlier, an extensive body of studies has provided evidence supporting effects of both surface-level functional and social demographic diversity on founding team formation. However, founding teams are not created automatically. Team formation requires human efforts to push collaboration between individuals and take actions to set up a team. After an individual's functional or social demographic features are perceived, team founders will contact each other, exchange information, and collaborate. Team is built as a result. Team collaboration is defined as the extent to which team members spend time and effort interacting with on another (Harrison et al., 2002). It is well accepted that member collaboration of a team is a key predictor of a team formation (e.g. Vanaelst, Clarysse, Wright, Lockett, Moray, \& S'Jegers, 2006; $\mathrm{Wi}$, Oh, Mun, \& Jung, 2009). Since more surface-level functional diversity is desired for the purposes of increasing human and social capital or improving the power of resource acquisition of the team, surfacelevel functional diversity will have a positive relationship with member collaboration. Whereas, since less surface-level social demographic diversity is desirable because people tend to work with people like themselves, surface-level social demographic diversity will have a negative relationship with member collaboration. Thus, I propose:

Proposition 3: Perceived surface-level functional diversity is positively associated with member collaboration that has a positive effect on team formation.

Proposition 4: Perceived surface-level social demographic diversity is negatively associated with member collaboration, so that perceived surface-level social demographic diversity will have a negative effect on team formation.

\section{Moderating Role of Interpersonal Feelings}

Feeling is a type of process-based affect. In contrast to mood and emotion affect that are not directed at a specific object, feeling is a person's affective reaction toward a target. Feeling can be evoked during an emotional experience, or activated and influenced by appraisal, conceptual, and perceptual processes 
(Izard, 1993). Therefore, feeling involves both affective and cognitive components. Previous literature has identified that feelings have both informational and motivational functions in determining people's decision-making, judgment, and behaviors (Izard, 2009; Pfister \& Bohm, 2008). However, not every feeling will be used as information in decision making or motivating actions. Prior research indicates that feelings are used as information in decisions only when its informational value is credited by the person (Pham, 1998). Put in another way, feelings will be abandoned if the person discards or discredits his/her feelings (Pham, 1998).

Interpersonal feelings are affective reactions to other people (Casciaro \& Lobo, 2008). A large body of psychological research on social judgment provides evidence that people judge others affectively, such as likable, nice, warm, friendly etc. Previous research shows that in addition to have additive effects (Bales, 1950; Levin \& Cross, 2004), interpersonal feeling and competence also have a collective effect on taskrelated interactions (Casciaro \& Lobo, 2008). At the initial stage of forming a founding team, a member chooses whom to approach or to avoid based on his/her perception of how much task resources potentially available from collaborating with another person (Casciaro \& Lobo, 2008). This member may perceive the surface-level functional diversity between him/her and that person and recognize that this person's competence at the venturing task is desired. However, if the member meanwhile has an affective feeling to this person and feels that this person is unpleasant or disliked, surface-level functional diversity in terms of task competence may fail to trigger further collaboration, nor founding team formation. Casciaro and Lobo (2008) study shows that positive interpersonal feelings increase a person's reliance on competence as a criterion for choosing task partners; whereas, negative interpersonal feelings reduce the reliance on task competence as a criterion for the choice of work partners. In the similar vein, the influences of perceived surface-level social demographic diversity on collaboration also depend on interpersonal feelings between new venture team founders. Although team members may have diverse social demographic characteristics, if they have positive interpersonal feelings, collaboration is still possible. Thus:

Proposition 5: The effect of perceived surface-level functional diversity on team collaboration is moderated by interpersonal feelings. Positive interpersonal feelings facilitate perceived surface-level functional diversity and collaboration relationship. Negative interpersonal feelings weaken this relationship.

Proposition 6: The effect of perceived surface-level social demographic diversity on team collaboration is moderated by interpersonal feelings. Positive interpersonal feelings offset the negative effect of perceived surface-level social demographic diversity on collaboration. Negative interpersonal feelings strengthen this effect.

\section{DISCUSSION AND IMPLICATION}

This paper extends a prominent view of diversity literature to entrepreneurship. It proposes a model that examines the influences of surface vs. deep level diversity, actual vs. perceived diversity on founding team formation. It also explores the role of interpersonal feelings play on these relationships. I propose that diversity influences founding team formation at both surface (functional and social demographic) and deep (psychological and cognitive) levels. At the initial stage of founding team formation, when deep-level diversity is not unfolded, surface-level diversity reflects the effects of perceived diversity on team integration. Interpersonal feelings moderate these relationships.

This paper has several contributions to the current literature. First, this paper helps explain contradictory findings of diversity effects on founding team formation and performance. Diversities among founding team members at surface-level are not sufficient to determine successful team formation and performance. Deep-level diversities within a founding team are more important predictors. Second, this paper extends the psychological affect literature on interpersonal feelings to founding team context. This paper adds to both entrepreneurships founding team and psychological affect literature a perspective on the interplay of affect and perceived diversity in founding team formation and performance. Third, in addition to providing 
insights into entrepreneurship founding team and affect literature, this paper also contributes to the diversity literature by proposing deep-level cognitive diversity into the category of deep-level diversity.

This paper also has practical implications for entrepreneurs. As a member of founding team, one may consider the potential effects of perceived surface and deep level diversities and seek to actively design and manage a team to be more effective. Improved awareness of the role of interpersonal feeling is also important to effectively establish a founding team and successful manage a venture.

\section{Future Research}

This paper one of few studies that explore the effects of deep-level vs. surface-level diversity on founding team formation. Any scholars who are familiar with entrepreneurial founding team dynamisms will know there is no single path from founding team formation to performance, nor a simple formulation of founding team success. The relationship between founding team diversity and the team performance are still far from comprehensive. It is highly possible that there are other factors other than interpersonal feelings influencing the relationship of diversity and team performance. Empirical studies are needed to test propositions of this paper. More research also needs to be focused on how to actively design and manage founding team to be more effective, and how to train entrepreneurship students with desired cognitive and affective capabilities to deal with founding team diverse issues. We hope this article can provide insights and severs as a catalyst calling for more detailed look at the founding team diversity issues in the context of entrepreneurship.

\section{CONCLUSION}

Founding team has been become one of the most important themes that interest entrepreneurship scholars. The goal of this paper is to extend one prominent view in the diversity literature to entrepreneurship. This study will make an important contribution to our understanding of how multiple types of member diversities influence founding team formation, functioning, and performance at different stages; and the role interpersonal feelings play during the process.

\section{REFERENCES}

Bales, R.F. (1950). Interaction process analysis. Cambridge, Mass.

Baron, R.A. (2008). The role of affect in the entrepreneurial process. Academy of Management Review, $33(2), 328-340$.

Becker, G.S. (1964). Human capital: A theoretical analysis with special reference to education. National Bureau for Economic Research. Columbia University Press: New York and London.

Beckman, C.M. (2006). The influence of founding team company affiliations on firm behavior. Academy of Management Journal, 49(4), 741-758.

Bell, S.T. (2007). Deep-level composition variables as predictors of team performance: A meta-analysis. Journal of Applied Psychology, 92(3), 595.

Burt, R.S. (1992). The Social Structure of Competition.

Cardon, M.S., Wincent, J., Singh, J., \& Drnovsek, M. (2009). The nature and experience of entrepreneurial passion. Academy of Management Review, 34(3), 511-532.

Casciaro, T., \& Lobo, M.S. (2008). When competence is irrelevant: The role of interpersonal affect in task-related ties. Administrative Science Quarterly, 53(4), 655-684.

Chandler, G.N., \& Hanks, S.H. (1998). An examination of the substitutability of founders human and financial capital in emerging business ventures. Journal of Business Venturing, 13(5), 353-369.

Chandler, G.N., \& Lyon, D.W. (2001). Issues of research design and construct measurement in entrepreneurship research: The past decade. Entrepreneurship Theory and Practice, 25(4), 101113. 
Chen, X-P., Yao, X., \& Kotha, S. (2009). Entrepreneur passion and preparedness in business plan presentations: A persuasion analysis of venture capitalists' funding decisions. Academy of Management Journal, 52(1), 199-214.

Chowdhury, S. (2005). Demographic diversity for building an effective entrepreneurial team: Is it important? Journal of Business Venturing, 20(6), 727-746.

Devine, D.J., \& Philips, J.L. (2001). Do Smarter Teams Do Better A Meta-Analysis of Cognitive Ability and Team Performance. Small Group Research, 32(5), 507-532.

Eesley, C.E., Hsu, D.H., \& Roberts, E.B. (2014). The contingent effects of top management teams on venture performance: Aligning founding team composition with innovation strategy and commercialization environment. Strategic Management Journal, 35(12), 1798-1817.

Ensley, M.D., \& Hmieleski, K.M. (2005). A comparative study of new venture top management team composition, dynamics and performance between university-based and independent start-ups. Research Policy, 34(7), 1091-1105.

Forbes, D.P., Borchert, P.S., Zellmer-Bruhn, M.E., \& Sapienza, H.J. (2006). Entrepreneurial team formation: An exploration of new member addition. Entrepreneurship Theory and Practice, $30(2), 225-248$.

Hannan, M.T., \& Freeman, J. (1984). Structural inertia and organizational change. American Sociological Review, pp. 149-164.

Harrison, D.A., Price, K.H., \& Bell, M.P. (1998). Beyond relational demography: Time and the effects of surface-and deep-level diversity on work group cohesion. Academy of Management Journal, 41(1), 96-107.

Harrison, D.A., Price, K.H., Gavin, J.H., \& Florey, A.T. (2002). Time, teams, and task performance: Changing effects of surface-and deep-level diversity on group functioning. Academy of Management Journal, pp. 1029-1045.

Izard, C. (1993). Four systems for emotion activation: Cognitive and noncognitive processes. Psychological Review-New York, 100, 68-68.

Izard, C. (2009). Emotion theory and research: Highlights, unanswered questions, and emerging issues. Annual Review of Psychology, 60, 1-25.

Jackson, S.E., May, K.E., \& Whitney, K. (1995). Understanding the dynamics of diversity in decisionmaking teams. Team Effectiveness and Decision Making in Organizations, 204, 261.

Kamm, J.B., \& Nurick, A.J. (1993). The stages of team venture formation: A decision-making model. Entrepreneurship Theory and Practice, 17, 17-17.

Knouse, S., \& Chretien, D. (1996). Workforce diversity and TQM. Human Resources Management Perspectives on TQM: Concepts and Practices, pp. 261-274.

Lawrence, B.S. (1997). The Black Box of Organizational Demography. Organization Science, 8(1), 1-22.

Levin, D.Z., \& Cross, R. (2004). The strength of weak ties you can trust: The mediating role of trust in effective knowledge transfer. Management Science, 50(11), 1477-1490.

Levine, J.M., \& Moreland, R.L. (1990). Progress in small group research. Annual Review of Psychology, $41(1), 585-634$.

Martinez, G.M, Zouaghi, F, \& Marco, T.G. (2017). Diversity is strategy: The effect of R\&D teach diversity on innovative performance. $R \& D$ Management, 47(2), 311-329.

Milliken, F.J., \& Martins, L.L. (1996). Searching for common threads: Understanding the multiple effects of diversity in organizational groups. Academy of Management Review, pp. 402-433.

Pfeffer, J., \& Salancik, G.R. (1978). The external control of organizations: A resource dependence approach. NY: Harper and Row Publishers.

Pfister, H., \& Bohm, G. (2008). The multiplicity of emotions: A framework of emotional functions in decision making. Judgment and Decision Making, 3(1), 5-17.

Pham, M. (1998). Representativeness, relevance, and the use of feelings in decision making. Journal of Consumer Research, 25(2), 144-159.

Randel, A.E., \& Jaussi, K.S. (2003). Functional background identity, diversity, and individual performance in cross-functional teams. Academy of Management Journal, 46(6), 763-774. 
Ruef, M., Aldrich, H.E., \& Carter, N.M. (2003). The structure of founding teams: Homophily, strong ties, and isolation among US entrepreneurs. American Sociological Review, 68(2), 195-222.

Shane, S.A. (2003). A general theory of entrepreneurship: The individual-opportunity nexus. Edward Elgar Pub.

Sine, W.D., Mitsuhashi, H., \& Kirsch, D.A. (2006). Revisiting Burns and Stalker: Formal Structure and New Venture Performance in Emerging Economic Sectors. Academy of Management Journal, 49(1), 121-132.

Sudek, R. (2006). Angel investment criteria. Journal of Small Business Strategy, 17(2), 2007.

Tajfel, H. (2010). Social identity and intergroup relations. Cambridge University Press.

Tasheva, \& Hillman. (2019). Integrating Diversity at Different Levels: Multilevel Human Capital, Social Capital, and Demographic Diversity and Their Implications for Team Effectiveness. Academy of Management Review, 14(4), 746-765.

Turner, J.C. (1982). Towards a cognitive redefinition of the social group. Social Identity and Intergroup Relations, pp. 15-40.

Vanaelst, I., Clarysse, B., Wright, M., Lockett, A., Moray, N., \& S'Jegers, R. (2006). Entrepreneurial team development in academic spinouts: An examination of team heterogeneity. Entrepreneurship Theory and Practice, 30(2), 249-271.

Wi, H., Oh, S., Mun, J., \& Jung, M. (2009). A team formation model based on knowledge and collaboration. Expert Systems With Applications, 36(5), 9121-9134.

Williams, K., \& O'Reilly, C. (1998). The complexity of diversity: A review of forty years of research. Research in Organizational Behavior, 21, 77-140.

Yu, L. (2002). Does diversity drive productivity? MIT Sloan Management Review, 43(2), 17. 